Marta Hałas-Wiśniewska ${ }^{1,2^{*}}$, Wioletta Zielińska ${ }^{1,2^{*}}$, Karolina Matulewicz², Anna Kokocha ${ }^{2}$, Agnieszka Nawrocka², Maciej Rydzkowski², Iwona Adamczyk², Magdalena Izdebska' ${ }^{1}$, Alina Grzanka ${ }^{1}$

${ }^{1}$ Department of Histology and Embryology, Nicolas Copernicus University in Toruń, Faculty of Medicine,

Collegium Medicum in Bydgoszcz, Poland

${ }^{2}$ Students research group of Cell Biology and Ultrastructure at Department of Histology and Embryology,

Nicolaus Copernicus University in Toruń, Collegium Medicum in Bydgoszcz, Poland

*These authors contributed equally to this work

\title{
The influence of house dust extract on normal lung cell Mrc5 and non-small lung carcinoma A549
}

\author{
Corresponding author: \\ Marta Hałas-Wiśniewska \\ Department of Histology \\ and Embryology \\ Nicolaus Copernicus University \\ in Toruń \\ Collegium Medicum in Bydgoszcz \\ 24 Karłowicza St. \\ 85-092 Bydgoszcz, Poland \\ e-mail: marciah88@wp.pl \\ Phone: +48525853725 \\ Fax: +48525853734
}

\begin{abstract}
Introduction. Desensitisation is a therapeutic method of allergic disease treatment, but its impact on the cellular level remains to be elucidated. The purpose of this study was to identify the influence of house dust extract on two cell lines types: non-small lung cancer A549 and non-cancerous lung fibroblast Mrc5. Furthermore, we analysed cell viability, type of cell death, and reorganisation of mainly cytoskeletal proteins such as vimentin, F-actin, and $\beta$-tubulin.

Material and methods. To determine the cell viability, the MTT test was used. The type of cell death was analysed using double staining of annexin $\mathrm{V}$ and iodide propidium. The reorganisation of cytoskeletal proteins was evaluated by fluorescent staining and microscopy observation.

Results. Our data presented non-statistical differences in a population of live, apoptotic, and necrotic cells. We did not observe significant abnormalities in cytoskeletal reorganisation. Moreover, Mrc5 cell line exhibited a lower sensitivity for house dust extract in comparison to A549 cell line.

Conclusions. Our study suggests that desensitisation has no significant influence on survival and cytoskeleton in both cell lines, which correlate with potential use of this method in cancer patients. Obviously, the choice of these kinds of treatment should be used carefully in consultation with a specialist. Additionally, to our knowledge, it was the first presentation of the influence of house dust extract on cells in the context of the main cytoskeletal reorganisations.

Key words: house dust extract, cell death, cytoskeleton, A549, Mrc5
\end{abstract}

Med Res J 2017; 2 (3): 102-110
Volume 2, Number 3, 102-110 10.5603/MRJ.2017.0013 Copyright (C) 2017 Via Medica ISSN 2451-2591

\section{Introduction}

Home dust is a complex mixture of organic substances (epidermis), inorganic substances (sand), and microorganisms (fungi, moulds, mites). The ratio of individual components of dust depends on the location of the collected sample and the type of surface on which the particles settles. Near the front door it will be mostly sand, and fragments of plants and insects, while near beds and on mattresses will be mainly scurf, fungi, and mites [1]. The dead epidermis, which fades from the surface of human skin, is pre-decomposed by fungi, and then becomes a source of nutrition for mites. The relationship between house dust mites (HDM) and allergy has been a topic of discussion since 1928 [2], when German scientist Dekker first identified the mites and their parts as allergens. However, this topic did not attract the attention of researchers until 1964, when Voorhorst et al. re-examined the connection between allergy and house dust mites [3]. Since then, this topic has been the subject of intense discussions in both scientific and non-scientific circles, as the incidence of allergies has increased significantly over the last decades and it has been perceived as a civilization disease. One side of the discussion claims that allergies are the result of excessive cleanliness, which does not allow for the full development of the immune system, and in turn leads to over-reaction to harmless agents [4]. In contrast, another group claims that it is the contact with dirt that causes allergic diseases [5]. The truth probably lies 
somewhere in the middle. Large settling particles are harmless to a healthy person, while smaller particles, called microdust, can cause an adverse effect. Microdust comes mainly from combustion processes. They are so small that they can penetrate into the alveoli, where they are treated as foreign bodies and cause inflammation [6]. The situation is diametrically different for individuals suffering from allergy and asthma, whose reactions to agents that are neutral for healthy people cause abnormal, excessive reaction. Exposure to dust can lead to exacerbation of the symptoms of the disease and even to the closure of the airways as a result of contraction of the bronchial wall muscles. Exposure to allergens may also cause a runny nose, fever, or rash. It has also been shown that dust in people with allergic asthma induces an inflammatory response and increases the production of free radicals, leading to oxidative DNA damage and lipid peroxidation [7].

So far there are three ways to reduce the symptoms of allergies. The first method is pharmacological treatment using antihistamine drugs. Drug particles bind to the $\mathrm{H} 1$ receptor competing for a place with histamine molecules and block its action. These drugs, although effective, do not cure the cause, but only reduce the symptoms. Moreover, their use, as well as the use of each drug, is associated with side effects like drowsiness, headaches, dizziness, and nervousness. Pharmacological therapy is also associated with the necessity of daily drug intake. The second way is to avoid contact with the allergen, which, as in the case of dust or pollens, is not always possible. In a study conducted by Murray and Ferguson limiting contact with mites by using certain steps to prevent their development, such as plastic bed and mattress pads, has proven to be effective in reducing the frequency and severity of asthma attacks in children [8]. However, earlier studies by Burr et al. did not bring similar results for adults [9] or for children [10]. Thus, the effectiveness of this solution remains unexplained. The third way to fight allergies is desensitisation. Desensitisation is a long-term process of administering to the patient increased dosage of allergen. The extract is given every 7-14 days for 2-3 months. Subsequent maintenance treatment is then administered by using the same dose of allergen for 3-5 years every 4-6 weeks. Although desensitisation is a long-term and expensive process, it is the only method that cures the cause of allergy and not only its symptoms. Our aim was to investigate the effect of house dust extract (HDE) used for immunotherapy on normal cells derived from the respiratory system - Mrc5 cell line, and on non-small cell lung cancer - A549 cell line, thereby assessing the safety of desensitisation. Here, we describe for the first time the impact of the above-mentioned allergen on cytoskeletal reorganisation.

\section{Material and methods}

\section{Cell culture and treatment}

The non-small cell lung carcinoma line A549 and normal human lung fibroblast cell line Mrc5 were incubated in Dulbecco's Modified Eagle Medium (DMEM) and Minimum Essential Medium (MEM) medium base with the addition of $10 \%$ fetal bovine serum and antibiotics, respectively. The cells were grown in standard conditions (at $37^{\circ} \mathrm{C}$ and in humidified $5 \% \mathrm{CO}_{2}$ atmosphere). For the following studies, A549 and Mrc5 cells were seeded in six-well and 12-well plates and cultured with house dust extract for 24 hours. The cell culture was divided into four groups:

- control cells Mrc5;

- control cells A549;

- Mrc5 cell treatment with house dust extract (HDE);

- A549 cells with the addition of house dust extract.

The house dust extract was a mixture of Dermatophagoides farinae (50\%; Der f) and Dermatophagoides pteronyssinus (50\%; Der $p$ ), which is commercially used for desensitisation. In order to select the appropriate dose of house dust extract, we used a range of concentrations from 0 to 750 therapeutic units (TU; standardisation of allergoids). Finally, for the next experiments, a concentration of 75 TU was chosen.

\section{MTT assay}

In order to the evaluate the survival of treated cells, colorimetric assay MTT (Sigma-Aldrich) was used. The cells were grown on 12-well plates and treated with different concentrations of house dust extract (0-750 TU). After 24-h culture, cells were washed with PBS and incubated with MTT solution $(5 \mathrm{mg} / \mathrm{mL})$ in the ratio 9:1 for three hours. The formazan crystals were dissolved in 2-isopropanol (10 min, $37^{\circ} \mathrm{C}$; Avantor). Finally, the absorbance of each dose was read at a wavelength $570 \mathrm{~nm}$ using a spectrophotometer (Spectra Academy, K-MAC). The dye absorbance of control cells was assumed as $100 \%$, and the cell viability was calculated as the percentage of MTT reduction.

\section{Cell death}

The effect of house dust extract on cell death in A549 and Mrc5 cells were analysed by double staining Annexin V Alexa Fluor 488 (AV) and lodide Propidium (PI) (Invitrogen/Life Technologies). After trypsinisation, the cells were resuspended in actin binding buffer (ABB; Invitrogen/Life Technologies) and incubated with annexin $\mathrm{V}$ and iodide propidium for 20 and 5 minutes, respectively (room temperature - RT, dark). The population of live, apoptotic, and necrotic cells were analysed using a Tali Image-based cytometer (Invitrogen/Life Technologies). 


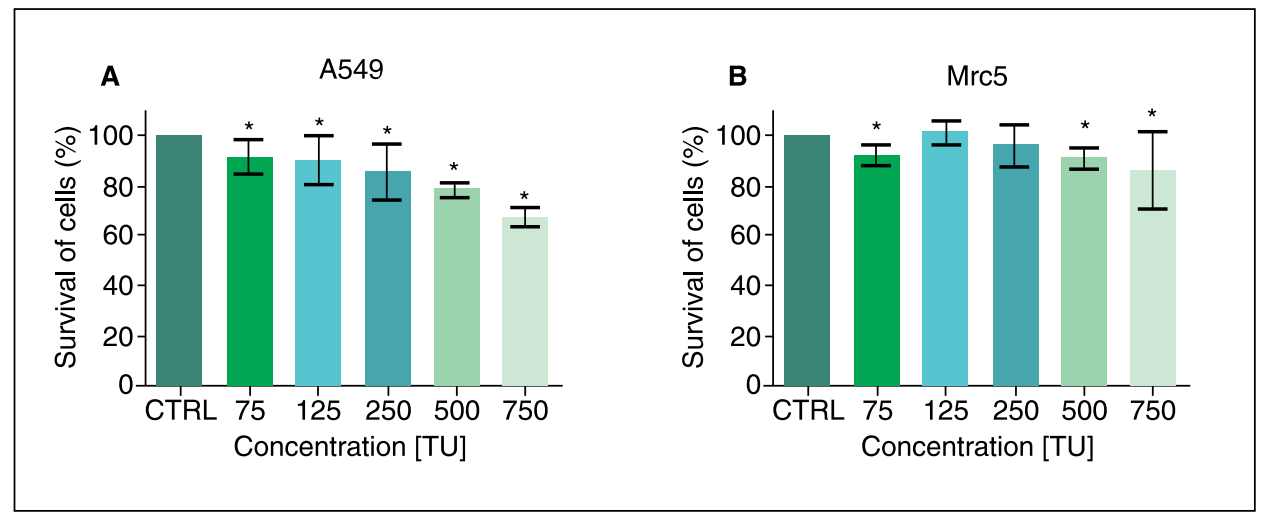

Figure 1. The MTT analysis of A549 (A) and Mrc5 (B) cell viability after house dust exposure. The cells were exposed to house dust extract in a concentration from 0 to 750 therapeutic units for $24 \mathrm{~h}$. The results showed dose-dependent and statistically significant reduction of viability in A549 cells. In the case of Mrc5, only 75, 500, and 750 TU caused a statistically significant decrease in cell survival. Data of each bar are shown as the mean of three independent experiments, and the statistically significant differences are noted by an asterisk $\left(^{*}\right)$

\section{Fluorescence staining}

The structures of the main cytoskeletal proteins were analysed by fluorescence staining. After culture cells were fixed in $4 \%$ paraformaldehyde (Serva), washed in phosphate-buffered saline (PBS; $3 \times 5 \mathrm{~min}, \mathrm{RT}$ ), and blocked with $1 \%$ bovine serum albumin (BSA; $20 \mathrm{~min}$, $\mathrm{RT}$, Sigma-Aldrich). In order to visualize $\beta$-tubulin, cells were prefixed according to the protocol described previously [11]. Then, the cells were incubated with primary antibodies: for vimentin (anti-mouse vimentin, 1:70, $1 \mathrm{~h}, \mathrm{RT}$; Sigma-Aldrich), $\beta$-tubulin (anti-mouse $\beta$-tubulin, 1:65, $1 \mathrm{~h}$, RT; Sigma-Aldrich), and F-actin (Alexa Fluor 488 phalloidin, 1:40, $20 \mathrm{~min}, \mathrm{RT}$, Invitrogen), respectively. After washing with PBS $(3 \times 5 \mathrm{~min}$, RT), cells were labelled with secondary antibodies: Alexa Fluor 488 goat anti-mouse IgG (for vimentin; 1:100, RT, Invitrogen) and anti-mouse IgG-TRITC (for microtubule; 1:85, RT, Sigma-Aldrich). The cell nuclei were stained with DAPI $(1: 2000 ; 10$ min, RT, Sigma Aldrich). The reorganisation of the cytoskeleton was analysed and photographed using a Nikon Eclipse E800 fluorescence microscope (Nikon; Tokyo, Japan) and NIS-Elements 4.0 software (Nikon).

\section{The statistical analysis}

The statistical analysis was performed with GraphPad Prism 5.0 (GraphPad Software). The data are presented as the mean \pm standard deviation (SD) and considered statistically significant at $p<0.05$ (marked by an asterisk*). The one-sample t-test was used to evaluate the statistical differences between the treated group and control cells with a hypothetical value of 100 (MTT analysis). In turn, a non-parametric Mann-Whitney U test was performed in cell death analysis.

\section{Results}

\section{MTT analysis}

At first, we evaluated the impact of house dust extract in different doses on the viability of normal lung fibroblast cell line Mrc5 as well as on non-small cell lung cancer A549. For that purpose, we treated both cell lines with house dust extract at concentrations of $75,125,250,500$, and 750 TU for 24 hours, and then the MTT assay was performed. For A549 cell line, the cell viability decreased in a dose-dependent manner and the results were statistically significant (Fig. 1A). In the case of Mrc5 cell line only at 75, 500, and 750 TU were statistically significant differences observed in comparison to control cells; however, these differences were smaller than for A549 cells, suggesting that normal lung fibroblast cell lines are less sensitive to the effects of household dust extract and we considered Mrc5 cell line as a positive control (Fig. 1B).

\section{Cell death analysis}

Next, we analysed the influence of extract on apoptosis and necrosis frequency after 24 hours of incubation with a 75-TU dose of house dust extract because it was the smallest dose causing a significant decrease in cell viability in the MTT test. In this order, double-staining with annexin $\mathrm{V}(\mathrm{AV})$ and propidium iodide (PI) was performed. On this basis, we distinguish three cell populations: viable (AV-/PI-), apoptotic (AV+/ (PI-), and necrotic (AV-/PI+). The percentage of cells in each population was rated using a Tali Image-Based Cytometer. Total apoptosis stands for the sum of early and lately apoptotic cells. In the case of non-small lung cancer cells, the data showed no significant differences 


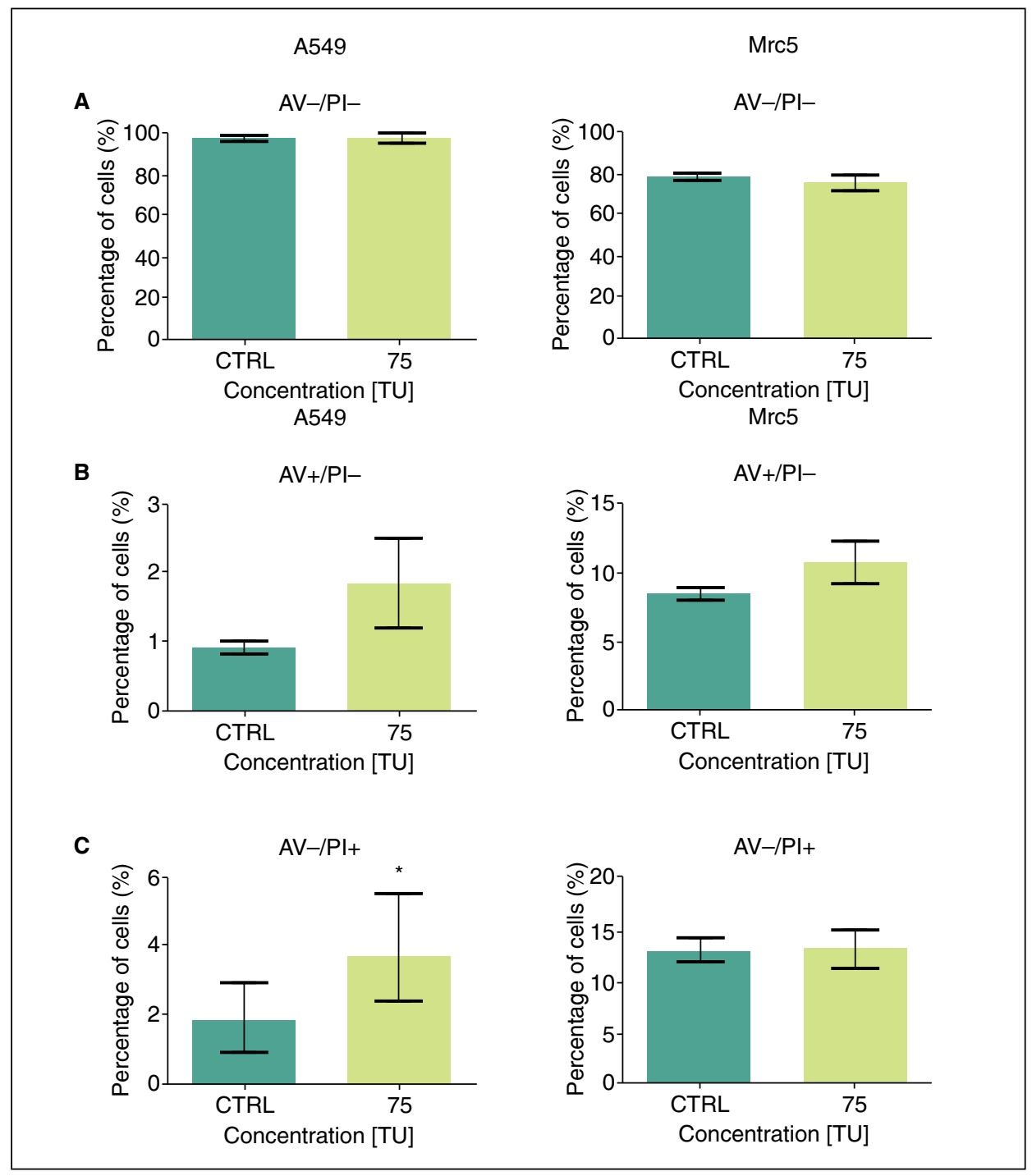

Figure 2. The effect of house dust extract on the type of cell death. The A549 and Mrc5 cell lines were incubated with house dust extract $(75 \mathrm{TU})$ for $24 \mathrm{~h}$ and double-stained with annexin V Alexa Fluor 488 and propidium iodide. The data showed no statistical differences in the percentage of live AV-/PI- (A), apoptotic AV+/ PI- (B), and necrotic cells AV-/ $/ \mathrm{PI}+(\mathbf{C})$ in both cell lines. CTRL — control cells. The results were analysed using a non-parametric Mann-Whitney $\mathrm{U}$ test (a statistically significant at $p<0.05$ ), marked by an asterisk ( ${ }^{*}$ )

in the percentage of live or apoptotic cells, but the level of necrosis increased from $1.89 \%$ to $3.99 \%$. Moreover, this test also confirmed the lower sensitivity of Mrc5 cell line to the extract - significant differences in cell percentages in any of the three cell populations were not observed (Fig. 2).

\section{Analysis of cytoskeletal proteins}

Immunofluorescent labelling was used to determine the effect of dust extract on the structure of the main cytoskeletal components - vimentin, F-actin, and $\beta$-tubulin. For Mrc5 cell line, no significant differences in cytoskeleton structure of the control and study groups were observed. The only exception was a single cell with a slightly extended structure of vimentin (Fig. 3F). In the case of A549, the first noticeable difference was the decrease in cell density and the level of F-actin fluorescence intensity in comparison to untreated cells (Fig. 3D). Many of the mitotic cells were visible in the control group, which was not observed in the cells treated with the house dust extract (Fig. 4A and 4B). For study group cells in A549 and Mrc5, there were also cases of mitotic catastrophe (giant and multinucleated cells), which is probably the second type of A549 cell death caused by house dust extract (Fig. 3D, Fig. 4B). 


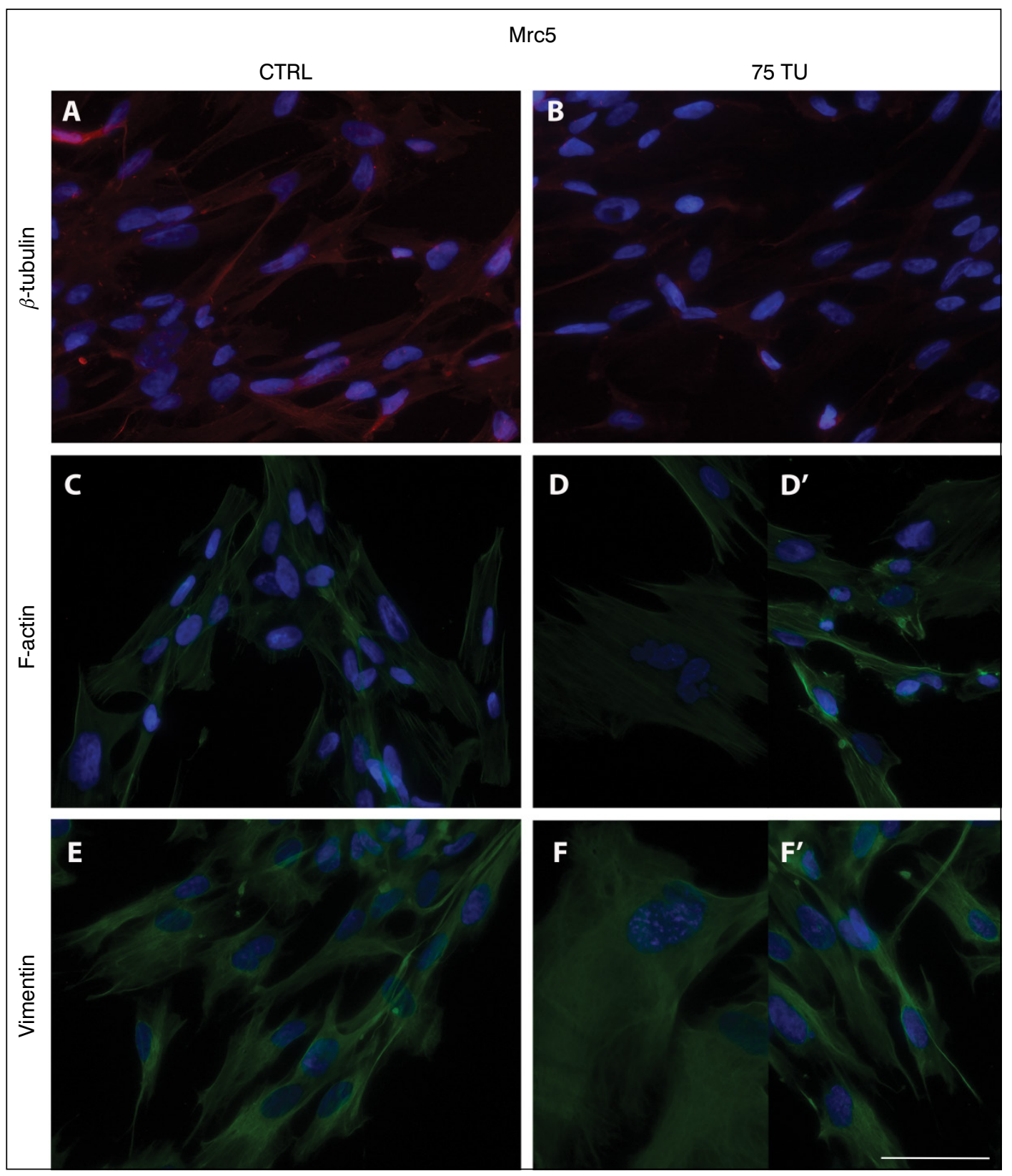

Figure 3. The effect of house dust extract on the induction of cytoskeletal reorganisation in Mrc5 cell line. The staining of $\beta$-tubulin, F-actin, and vimentin. A, C, E - control cells; B, D, D', F, F' - cells after 24 h treatment with 75 TU house dust extract. The small population of cells with stress fibres (D) and a single cell with a slightly extended structure of vimentin (F) were noticed. Bar $=50 \mu \mathrm{m}$

Furthermore, in our study, a minor quantity of stress fibres were also noticed in the above-mentioned cell lines (Fig. 3D).

\section{Discussion}

Nowadays, allergies are the most common chronic illnesses in children, adolescents, and adults, resulting in a severe problem for worldwide public health. Among the huge number of different allergens, house dust mite is one of the most common factors that induces an abnormal reaction of the immune system - allergy. Symptoms of these disorders are extremely problematic and hindering normal human functioning, and most of them require systematic treatment such as desensitisation. This problem also affects cancer patients, so the aim of our study 


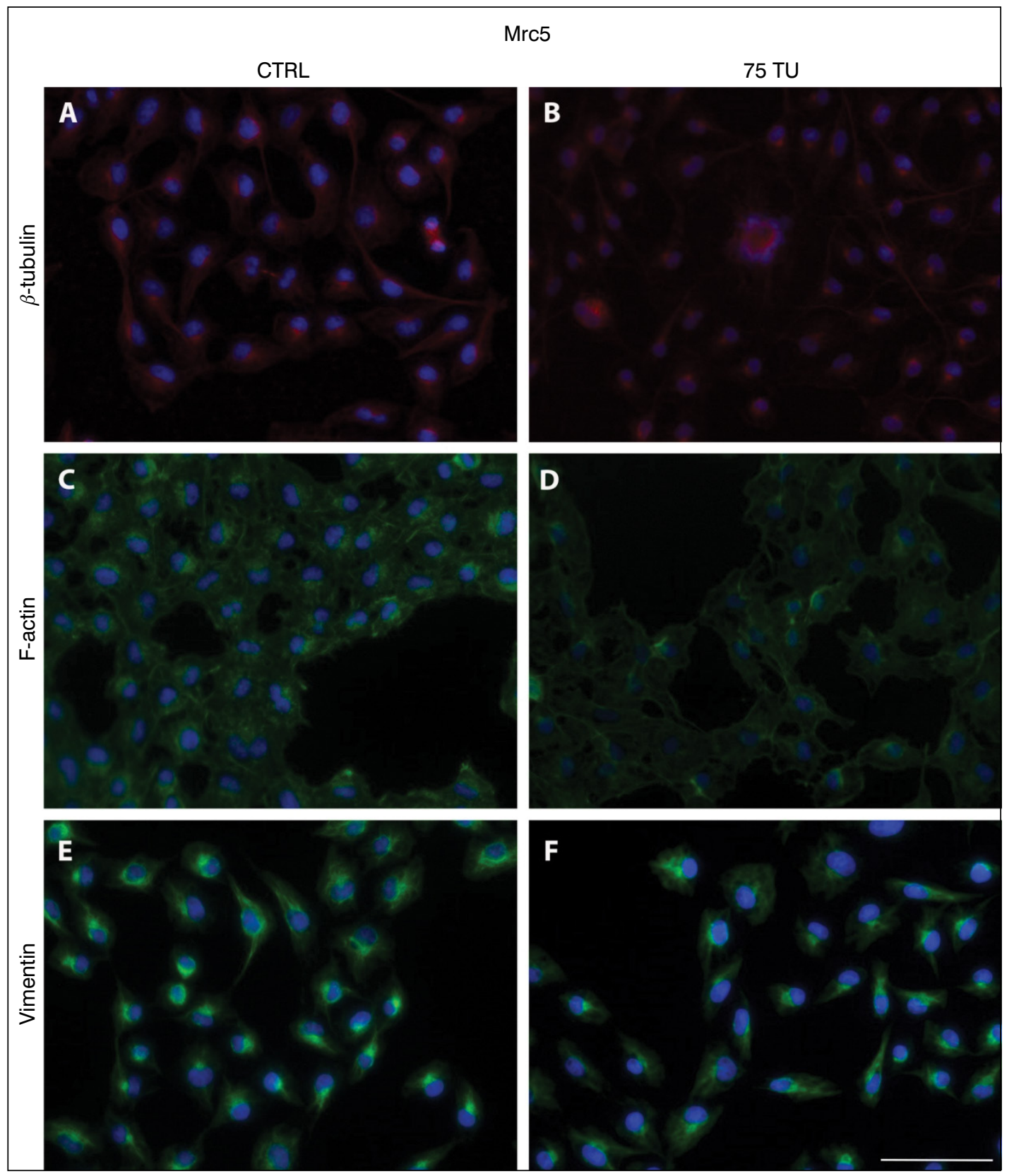

Figure 4. The effect of house dust extract on the induction of cytoskeletal reorganisation in $A 549$ cell line. The fluorescent staining of $\beta$-tubulin, F-actin, and vimentin. A, C, E - untreated cells; B, D, F - cells after 24-h exposure to 75 TU house dust extract. We observed the decrease in cell density and the level of F-actin fluorescence intensity (B). The presence of giant, multinucleated cells were noticed (D). Bar $=50 \mu \mathrm{m}$

was to evaluate the influence of house dust extract on the cellular processes, including cell death and reorganisation of the main cytoskeletal proteins in both non-small lung cancer cell A549 and normal lung fibroblast Mrc5.

The effect of house dust mites on the cellular level is still unknown. So far, researchers have focused mainly on the influence of these allergens on different cell lines, including normal human epidermal keratinocytes and dermal fibroblasts [12], primary human corneal epithelial cells (PHCE) [13], human bronchial epithelial cells (BEAS-2B) [14], immortalised cell lines (lung epithelial cells), and also (rarely) cancer cells such as human HepG2 [15], A549, and HeLa cell line [16].

Worldwide literature has reported that the common species of house dust mites - Dermatophagoides farinae (Derf) and Dermatophagoides pteronyssinus (Derp) — induce IL-6 and IL-8 secretion in a normal human der- 
mal fibroblast concentration-dependent manner [17]. These types of interleukins are characteristic for different immune response mechanisms in the human body, which can be caused by an allergy. Furthermore, other studies have shown that exposure to HDM may result in genotoxicity and cytotoxicity effects on bronchial epithelium [18] and human keratinocytes [19]. In the case of the human dermal endothelial cell, a study by Arlian et al. reported that the influence of the above-mentioned allergens on these types of cells stimulate the production of interleukin and adhesion molecules such as intercellular adhesion molecule 1 (ICAM-1), vascular cell adhesion molecule 1 (VCAM-1), and E-selectin [20]. Similarly, Asokananthan $\mathrm{N}$ et al. showed that an increase in the level of interleukin (IL-6 and IL-8) occurs in a time- and dose-dependent manner following treatment with clinical important cysteine protease allergen Der $f$ in A549 cell line. Their research showed that desensitisation may cause the activation of processes related to PAR-2 receptors (protease-activated receptor) located on the surface of the respiratory epithelial cells. On the other hand, the treatment with Dermatophagoides pteronyssinus resulted in NF-kappaB and mitogen-activated protein kinase (MAPK)-dependent secretion of interleukin, cytokines, and chemokines in bronchial BEAS-2B and human bronchial epithelial cells (NHBE) [21]. In turn, Xiang et al. observed the dose-dependent toxic effect of a dust mite on PHCE cell line. Their studies showed a reduction of cell viability and the higher level of biomarkers characteristic for oxidative stress. Also, they suggested that the mechanism of action of house dust extract is correlated with alterations of mRNA expression of antioxidant enzymes and pro-inflammatory mediators, which corresponded with reduction of mitochondrial membrane potential in PHCE cells [13].

In our study, we also applied a mixture of Dermatophagoides farinae and Dermatophagoides pteronyssinus. As mentioned, specific allergen immunotherapy (desensitisation) is a method based on the regular administration of small, gradually increasing concentrations of the allergen and consequently reduce or eliminate an organism's reactions to allergic factors. This kind of therapy is a long-term process, but it is successfully applied in both children and adult patients. Numerous studies have presented that low-dose desensitisation is ineffective, while high concentrations cause systemic reaction $[22,23]$. The optimal dose of allergen extract is characterised by satisfactory clinical results, not producing any serious side effects, and it is estimated for most allergens at 5-20 $\mu \mathrm{g}$ per one injection/month. It should also be taken into consideration that an adjusted dosing schedule is provided by manufacturers of particular vaccines. The allergen extract used in our study is recommended for therapeutic use according to the instruction diagrams, with an initial concentration of $5000 \mathrm{TU} / \mathrm{mL}$. However, this concentration is suitable for humans. As our research material were cell lines for all experiments, accordingly lower doses of house dust extract (75 TU) were applied.

The first aim of our investigation was to evaluate the influence of commercially available house dust extract on the survival of two cell lines: cancerous non-small lung cells (A549) and non-cancerous lung fibroblast cells (Mrc5). For this purpose, we used test MTT, and the results for both cell types can be seen in Figure 1. We observed a dose-dependent decrease in viability of treated A549. In the case of Mrc5, the results were not clear, but we suggested that normal lung fibroblasts cells were less sensitive to incubation with house dust extract compared to cancerous cells. The next step was the analysis the type of cell death using annexin $V$ and propidium iodide double staining. The population of live, apoptotic, and necrotic cells were evaluated using a Tali Image-based cytometer, and the results revealed non-statistical differences in the percentage of viable and death cell in both A549 and Mrc5 cell lines. The only exception was the population of necrotic cells in the case of non-small cancer, where we noticed a minimal increase in comparison to control cells. However, these data suggest that exposure to house dust extract does not induce programmed cell death in selected cell lines. It is worth mentioning that this method allows us to distinguish only two types of cell death: apoptosis and necrosis. Moreover, the differences in the percentage of viable cells between MTT test and double-staining with Annexin V and PI may be caused by the occurrence of other types of cell death such as mitotic catastrophe. It must be pointed out that the incubation with house dust extract in cell culture probably resulted in a physical stress condition and consequently a minor reduction of the viability. Likewise, Xiang et al. also indicated that the presence of high concentrations of house dust mites inducing stress condition and leading to a higher percentage of cell death (in primary human corneal epithelial cells) [13].

It is known that cytoskeleton is the most important structure in the cell and it plays many important functions, including shape maintenance, motility, and mitosis [24]. In the presented study, we described for the first time the organisation of F-actin, vimentin, and $\beta$-tubulin after house dust mite exposure on A549 and Mrc5 cell line. Each of this cytoskeleton compounds are involved in key cellular processes and together form a specialised and unbroken network. Thus, microtubules ( $\beta$-tubulin) are responsible for cell division during chromosome separation and intracellular transport [25]. The intermediated filaments (vimentin) play roles in maintaining of cell shape, supporting and integrity of the cytoplasm [26]. In turn, filamentous actin (F-actin) is involved in adhesion, cell death, and migration [27]. Due to the significance of the main cytoskeletal proteins in 
cell functioning, we found it reasonable to assess these structures after contact with house dust extract. In the investigation, significant morphological abnormalities in A549 and Mrc5 were not observed, apart from the single cell with scattered cytoplasm. Furthermore, there was a lack of evidence of apoptosis hallmarks, but a small population of cells with typical features of mitotic catastrophe such as large size and multinucleated were noticed. Thus, this observation confirmed results from the analysis of MTT test and cell death. On the other hand, Fisher and Agrawal indicated the alterations in shape of dust-exposed PHCE cells from polygonal to spindle [28]. We assume that these alterations were a consequence of the different sensitivity of selected cell lines to house dust extract. Similarly, our fluorescence staining of cytoskeletal proteins such as F-actin revealed greater sensitivity in HDE-treated, non-small lung cancer cells, which was manifested by a decrease in the intensity of F-actin fluorescence. Furthermore, the presence of small population of cells with stress fibres were also observed in both A549 and Mrc5 cell lines. This structure of actin filamentous is characteristic for cells responding to their environment and changes in cell adhesion. Numerous studies have demonstrated a correlation between the presence of stress fibres and factors, which induce stress conditions in cell culture [29]. In the case of $\beta$-tubulin, we did not observe any changes in both cell lines. In turn, analysis of the intermediate filament network showed a single cell with a slightly extended structure of vimentin in Mrc5 (after 75 TU HDE). Nevertheless, we suggested that the scale of observed changes allows us to determine the low impact of house dust extract on the cytoskeleton in non-cancerous Mrc5 and cancerous A549 cell line, and confirmed our previous results. In the case of cancer patients, lack of significant changes in these cytoskeletal proteins involved in cell motility are very beneficial, especially in the context of the probability of metastasis.

\section{Conclusions}

In conclusion, the present investigation showed abnormal response of lung fibroblast Mrc5 and nonsmall lung cancer A549 cells to house dust mite, with cancerous cells showing higher sensitivity than non-cancerous cell line. Moreover, our study suggests that desensitisation has no significant influence on survival and cytoskeleton in the above-mentioned type of cells, which correlate with potential use of this method in cancer patients. Obviously, the choice of this treatment type should be used carefully and consulted with a specialist. Additionally, to our knowledge, there are no reports on the influence of house dust extract on cells in the context of the main cytoskeletal reorganisations.

\section{Conflict of interest: none declared}

Acknowledgments: This study was supported by a research task within the framework of the statutory activities and Student Researches (Nicolaus Copernicus University in Toruń, Faculty of Medicine, Collegium Medicum in Bydgoszcz)

\section{References}

1. Butte W. Heinzow B. Pollutants in house dust as indicators of indoor contamination. Rev Environ Contam Toxicol. 2002; 175: 1-46, indexed in Pubmed: 12206053

2. Dekker H. Asthma und Milben. Munchener Medizinische Wochenschrift. 1928; 75: 515.

3. Voorhorst R, Spieksma FT. Recent progress in the house dust mite problem. Acta Allergol. 1969; 24(2): 115-123, indexed in Pubmed: 5395982.

4. Weber J, Illi S, Nowak D, et al. Asthma and the hygiene hypothesis. Does cleanliness matter? Am J Respir Crit Care Med. 2015; 191(5): 522-529, doi: 10.1164/rccm.201410-18990C, indexed in Pubmed: 25584716.

5. Roberts JW, Wallace LA, Camann DE, et al. Monitoring and reducing exposure of infants to pollutants in house dust. Rev Environ Contam Toxicol. 2009; 201: 1-39, doi: 10.1007/978-1-4419-0032-6 1, indexed in Pubmed: 19484587

6. Lighty J, Veranth J, Sarofim A. Combustion Aerosols: Factors Governing Their Size and Composition and Implications to Human Health. Journal of the Air \& Waste Management Association. 2011; 50(9): 1565-1618, doi: 10.1080/10473289.2000.10464197.

7. Chan TK, Loh XYi, Peh HY, et al. House dust mite-induced asthma causes oxidative damage and DNA double-strand breaks in the lungs. J Allergy Clin Immunol. 2016; 138(1): 84-96.e1, doi: 10.1016/j. jaci.2016.02.017, indexed in Pubmed: 27157131

8. Murray AB, Ferguson AC. Dust-free bedrooms in the treatment of asthmatic children with house dust or house dust mite allergy: a controlled trial. Pediatrics. 1983; 71(3): 418-422, indexed in Pubmed: 6338475.

9. Burr ML, St Leger AS, Neale E. Anti-mite measurements in mite-sensitive adult asthma. A controlled trial. Lancet. 1976; 1(7955): 333-335, indexed in Pubmed: 54740

10. Burr ML, Dean BV, Merrett TG, et al. Effects of anti-mite measures on children with mite-sensitive asthma: a controlled trial. Thorax. 1980; 35(7): 506-512, indexed in Pubmed: 7001667.

11. Klimaszewska-Wiśniewska A, Hałas-Wiśniewska M, lzdebska M, et al. Antiproliferative and antimetastatic action of quercetin on A549 non-small cell lung cancer cells through its effect on the cytoskeleton. Acta Histochem. 2017; 119(2): 99-112, doi: 10.1016/j.acthis.2016.11.003, indexed in Pubmed: 27887793.

12. Arlian LG, Morgan MS, Peterson KT. House dust and storage mite extracts influence skin keratinocyte and fibroblast function. Int Arch Allergy Immunol. 2008; 145(1): 33-42, doi: 10.1159/000107464, indexed in Pubmed: 17703098.

13. Xiang P, He RW, Han YH, et al. Mechanisms of housedust-induced toxicity in primary human corneal epithelial cells: Oxidative stress, proinflammatory response and mitochondrial dysfunction. Environ Int. 2016; 89-90: 30-37, doi: 10.1016/j.envint.2016.01.008, indexed in Pubmed: 26826360.

14. King C, Brennan S, Thompson PJ, et al. Dust mite proteolytic allergens induce cytokine release from cultured airway epithelium. J Immunol. 1998; 161(7): 3645-3651, indexed in Pubmed: 9759888.

15. Kang $\mathrm{Y}$, Cheung $\mathrm{KC}$, Wong $\mathrm{MH}$. The use of cytokine array to examine cytokine profiles of two human cell lines exposed to indoor dust. Toxicol Lett. 2010; 199(3): 301-307, doi: 10.1016/j.toxlet.2010.09.012, indexed in Pubmed: 20883751

16. Asokananthan N, Graham PT, Stewart DJ, et al. House dust mite allergens induce proinflammatory cytokines from respiratory epithelial cells:

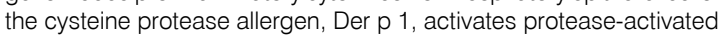
receptor (PAR)-2 and inactivates PAR-1. J Immunol. 2002; 169(8): 4572-4578, indexed in Pubmed: 12370395

17. Rockwood J, Morgan MS, Arlian LG. Proteins and endotoxin in house dust mite extracts modulate cytokine secretion and gene expression by dermal fibroblasts. Exp Appl Acarol. 2013; 61(3): 311-325, doi: 10.1007/s10493-013-9703-9, indexed in Pubmed: 23640713. 
18. Wong CK, Li MLY, Wang CB, et al. House dust mite allergen Der p 1 elevates the release of inflammatory cytokines and expression of adhesion molecules in co-culture of human eosinophils and bronchial epithelial cells. Int Immunol. 2006; 18(8): 1327-1335, doi: 10.1093/intimm/dxI065, indexed in Pubmed: 16798840.

19. Mascia F, Mariani V, Giannetti A, et al. House dust mite allergen exerts no direct proinflammatory effects on human keratinocytes. J Allergy Clin Immunol. 2002; 109(3): 532-538, indexed in Pubmed: 11898003.

20. Arlian LG, Elder BL, Morgan MS. House dust mite extracts activate cultured human dermal endothelial cells to express adhesion molecules and secrete cytokines. J Med Entomol. 2009; 46(3): 595-604 indexed in Pubmed: 19496432.

21. Osterlund C, Grönlund H, Polovic N, et al. The non-proteolytic house dust mite allergen Der $\mathrm{p} 2$ induce NF-kappaB and MAPK dependen activation of bronchial epithelial cells. Clin Exp Allergy. 2009; 39(8) 1199-1208, doi: 10.1111/j.1365-2222.2009.03284.x, indexed in Pubmed: 19486032

22. Bousquet J, Lockey RF, Malling H-J, et al. Immunoterapia alergenami: szczepionki terapeutyczne w chorobach alergicznych cz.I. Stanowisko Światowej Organizacji ZdrowiaAlergia Astma Immunologia. 2000; 5(1) 7-30 PMID. : 9860031

23. Calderón MA, Kleine-Tebbe J, Linneberg A, et al. House Dust Mite Respiratory Allergy: An Overview of Current Therapeutic Strate- gies. J Allergy Clin Immunol Pract. 2015; 3(6): 843-855, doi: 10.1016/j. jaip.2015.06.019, indexed in Pubmed: 26342746.

24. Fletcher DA, Mullins RD. Cell mechanics and the cytoskeleton. Nature. 2010; 463(7280): 485-492, doi: 10.1038/nature08908, indexed in Pubmed: 20110992

25. Etienne-Manneville S. Actin and microtubules in cell motility: which one is in control? Traffic. 2004; 5(7): 470-477, doi: 10.1111/j.16000854.2004.00196.x, indexed in Pubmed: 15180824

26. Ivaska J, Pallari HM, Nevo J, et al. Novel functions of vimentin in cell adhesion, migration, and signaling. Exp Cell Res. 2007; 313(10): 2050-2062, doi: 10.1016/i.yexcr.2007.03.040, indexed in Pubmed: 17512929

27. Pollard TD. The cytoskeleton, cellular motility and the reductionist agenda. Nature. 2003; 422(6933): 741-745, doi: 10.1038/nature01598, indexed in Pubmed: 12700767.

28. Fischer K, Agrawal D. Induction of epithelial-mesenchymal transition in house dust mite, ragweed, and alternaria sensitized and challenged mice. Journal of Allergy and Clinical Immunology. 2015; 135(2): AB62, doi: 10.1016/j.jaci.2014.12.1135.

29. Peterson LJ, Rajfur Z, Maddox AS, et al. Simultaneous stretching and contraction of stress fibers in vivo. Mol Biol Cell. 2004; 15(7): 3497-3508, doi: 10.1091/mbc.E03-09-0696, indexed in Pubmed: 15133124. 